\title{
Green Infrastructure Offset the Negative Ecological Effects of Urbanization and Storing Water in the Three Gorges Reservoir Area, China
}

\author{
Qipeng Liao ${ }^{1,2}$, Zhe Wang ${ }^{1}$ and Chunbo Huang ${ }^{3, *}$ \\ 1 School of Arts and Communication, China University of Geosciences, Wuhan 430078, China; \\ liaoqp@cug.edu.cn (Q.L.); 18222933115@163.com (Z.W.) \\ 2 Faculty of Fine Art, University of Barcelona, 08028 Barcelona, Spain \\ 3 Research Center for Spatial Planning and Human-Environment System Simulation, School of Geography \\ and Information Engineering, China University of Geosciences, Wuhan 430078, China \\ * Correspondence: huangchunbo@cug.edu.cn or poahcb@hotmail.com
}

Received: 28 September 2020; Accepted: 29 October 2020; Published: 2 November 2020

\begin{abstract}
Land use planning usually increases the uncertainties of the ecosystem structures and functions because various human demands usually bring both positive and negative ecological effects. It is critical for estimating various land use changes and their ecological effects, but the previous studies have failed to decouple the respective and the combined effects of different land use changes on ecosystem services. Net primary productivity (NPP) could be used to indicate many ecosystem services such as carbon sequestration and storage. Here, we employed a light use efficiency model to estimate the spatial and temporal dynamics of NPP in the Three Gorges Reservoir (TGR) area from 2000 to 2015, and designed four scenarios to analyze the relative roles of afforestation, urbanization and storing water on NPP dynamics. Our results documented that terrestrial NPP of the TGR area

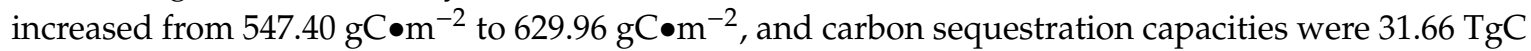
$\left(1 \mathrm{Tg}=10^{12} \mathrm{~g}\right)$ and $36.79 \mathrm{TgC}$ in 2000 and 2015, respectively. Climate change and land use change both could contribute to carbon sequestration with $4.08 \mathrm{TgC}$ and $1.05 \mathrm{TgC}$. Among these land use changes, only afforestation could sequester carbon with $2.04 \mathrm{TgC}$, while urbanization-induced and impoundment-induced emissions were $0.12 \mathrm{TgC}$ and $0.32 \mathrm{TgC}$, respectively, and other land use changes also could release $0.55 \mathrm{TgC}$ of carbon. This finding suggested that although positive and negative environmental effects happened simultaneously over the past decades, green infrastructure could effectively offset the carbon emissions from urbanization and storing water in the TGR area, which provides some fundamental supports for further ecological restoration and contributes to empowering land use policies towards carbon sequestration and storage at the regional scale.
\end{abstract}

Keywords: land use change; landscape planning; ecosystem services; ecological restoration; Carnegie-Ames-Stanford Approach (CASA)

\section{Introduction}

Increasing human activities have significantly altered the ecosystem function and service on terrestrial surfaces, especially in ecologically vulnerable areas [1,2]. It is of great significance for regional sustainable development to clarify the ecosystem evolution mechanism against the background of global climate change and intensified human activities [3]. Human activities (e.g., ecological restoration, green infrastructure construction and urbanization) and global climate change have significantly changed the landscape pattern, regional biodiversity and ecosystem functions [4,5]. However, previous studies lack an in-depth analysis of studies related to how land use change (such as green infrastructure construction, deforestation and urbanization) and climate change affect the regional 
ecological environments. This cannot effectively support the formulation of land use and ecological protection-oriented policies. Decoupling the effects of climate change and land use changes on the ecosystem is an effective means to expose the disturbances caused climate change and human activities on ecosystem services. In this context, it is necessary to analyze the impact of various land use change and climate change on the ecosystem structure and function.

Net primary productivity (NPP) is the total amount of organic matter accumulated by vegetation per unit of area per unit of time and represents the carbon sequestration capacity of vegetation [6,7]. As one of the most critical components of the carbon cycle in terrestrial ecosystems, NPP could be used to indicate many ecosystem services (e.g., carbon sequestration and storage, water conservation) $[6,8]$. Meanwhile, global NPP could refer to the biophysical limit for the human to live and survive on the earth [9]. NPP is mainly determined by the ecosystem structure, such as the configuration of vegetation [10] and the horizontal and vertical distributions of forests [11]. Many factors such as climate change [12,13], land use transition [14], and human disturbance [15] would change the ecosystem structures, which driving terrestrial NPP dynamics at various spatial scales. Therefore, it is vital to characterize and quantify the spatiotemporal variations of NPP as a result of various driving forces for land use planning and ecosystem regulation.

Numerous studies (e.g., Wu et al. [16], Gingrich et al. [17], Khalifa et al. [18]) have analyzed the spatiotemporal dynamics of terrestrial NPP at the regional scale and documented that human-induced land use change and climate change were among the primary driving forces for NPP dynamics [19]. Although some studies tried to decouple the individual effects of land use change and climate change, there was a large uncertainty for NPP dynamics due to the interaction effects of various land use changes $[9,16]$. For instance, the implementation of green infrastructure projects and urban sprawling could occur simultaneously at the regional scale [1]. The former such as afforestation or reforestation would increase the terrestrial NPP while the latter could decrease the terrestrial NPP. Therefore, the combined effects of ecological restoration and urbanization are complex and difficult to demonstrate for a regional study $[12,20]$. Consequently, it is important to quantitatively assess the magnitude and direction of the respective and the combined effects of various land use changes on NPP dynamics.

Generally, NPP could be assessed by field measurements and model estimations [21]. Field measurements are usually used at the local scale and can provide a high-precision NPP evaluation [22,23]. The eddy covariance technique is among the representative measuring methods and could collect valuable data such as carbon flux, water, and energy exchange [24,25]. However, field measurement is spatially limited and likely to be affected by the site conditions of the flux tower site. The NPP estimation models include statistical models [7,26,27], process-based models [28-30], and light use efficiency models [31-33], which can extrapolate over vast continental areas. The statistical model, with few input parameters and low evaluation accuracy, is generated by analyzing and modeling field measurement [26]. In contrast, the process-based model needs many input parameters and has high evaluation accuracy [34]. The light use efficiency model could spatially explicit information on carbon exchange at various spatial scales and have the greater potential to adequately address the conflict between the input data and the accuracy due to its theoretical basis and practicality [33].

Since the construction of the Three Gorges Dam Project in China, the Three Gorges Reservoir (TGR) area of the Yangtze River has attracted worldwide attention. The world's largest hydroelectric project could help to generate hydropower, control floods, and improve navigation [35,36], but carbon emissions have worsened due to the hydropower plant and infrastructure construction [37]. Moreover, Chongqing City, a rapidly developing municipality, is located to the southwest of the TGR area. The Western Development Project has promoted urban expansion and accelerated economic growth there, which has also increased carbon emissions in this region [37]. Meanwhile, the TGR area is one of the most ecologically vulnerable areas and suffers many environmental problems such as soil loss [36], nonpoint source pollution [38], and habitat fragmentation [39] because of its rugged topography and intensive human activities. The Chinese government has launched and implemented a series of green 
infrastructure projects, especially some key afforestation projects, to increase resilience, enhance the provision of ecosystem services, recover biodiversity and reduce the negative ecological effects [1,36], which also contributed to carbon sequestration and storage. Although some studies (such as Chen and Xiao [30], Zhao et al. [40], Xiao et al. [41]) have estimated and analyzed the spatiotemporal dynamics of terrestrial NPP in the TGR area, the overall and relative effects of these land use changes on NPP dynamic was poorly understood.

In this study, we used a light use efficiency model, Carnegie-Ames-Stanford Approach (CASA), to estimate the NPP of the TGR area and explored the spatiotemporal dynamics of NPP from 2000 to 2015. Meanwhile, we designed four scenarios to analyze the relative roles of afforestation, urbanization and storing water on NPP dynamics. Our study could provide fundamental support for further ecological restoration and green infrastructure planning in the TGR area and contribute to empowering land use policies towards carbon sequestration and storage at the regional scale. The specific objectives are as follows (1) estimate and characterize the spatiotemporal variation of NPP; (2) analyze the overall effects of climate and land use change on NPP dynamics; (3) demonstrate the relative effects of various land use changes on NPP dynamics.

\section{Materials and Methods}

\subsection{Study Area}

The TGR area is located in the upper and middle reaches of the Yangtze River (Figure 1), and lies between $28^{\circ} 31^{\prime} \sim 31^{\circ} 44^{\prime} \mathrm{N}$ and $105^{\circ} 50^{\prime} \sim 111^{\circ} 40^{\prime}$ E. It covers about $5.8 \times 10^{4} \mathrm{~km}^{2}$ and consists of 20 districts or counties (four in Hubei Province and 16 in Chongqing municipality), which are directly influenced by the construction of the Three Gorges Dam to store water. In this region, the mountainous areas account for more than $74 \%$ of the total area, and the hills account for $21.7 \%$, while the small plains alongside river valleys make up only $4.3 \%$. Meanwhile, the steep slope $\left(>25^{\circ}\right)$ accounts for $24.74 \%$ of the total area. The TGR area has a humid mid-subtropical monsoon climate, with a mean annual temperature of $20^{\circ} \mathrm{C}$ and mean annual precipitation of $1200 \mathrm{~mm}$. It is a typical biodiversity hotspot with rich plant resources in China. However, the historical land use types are mainly croplands because of the long-term anthropogenic activity and dense population.

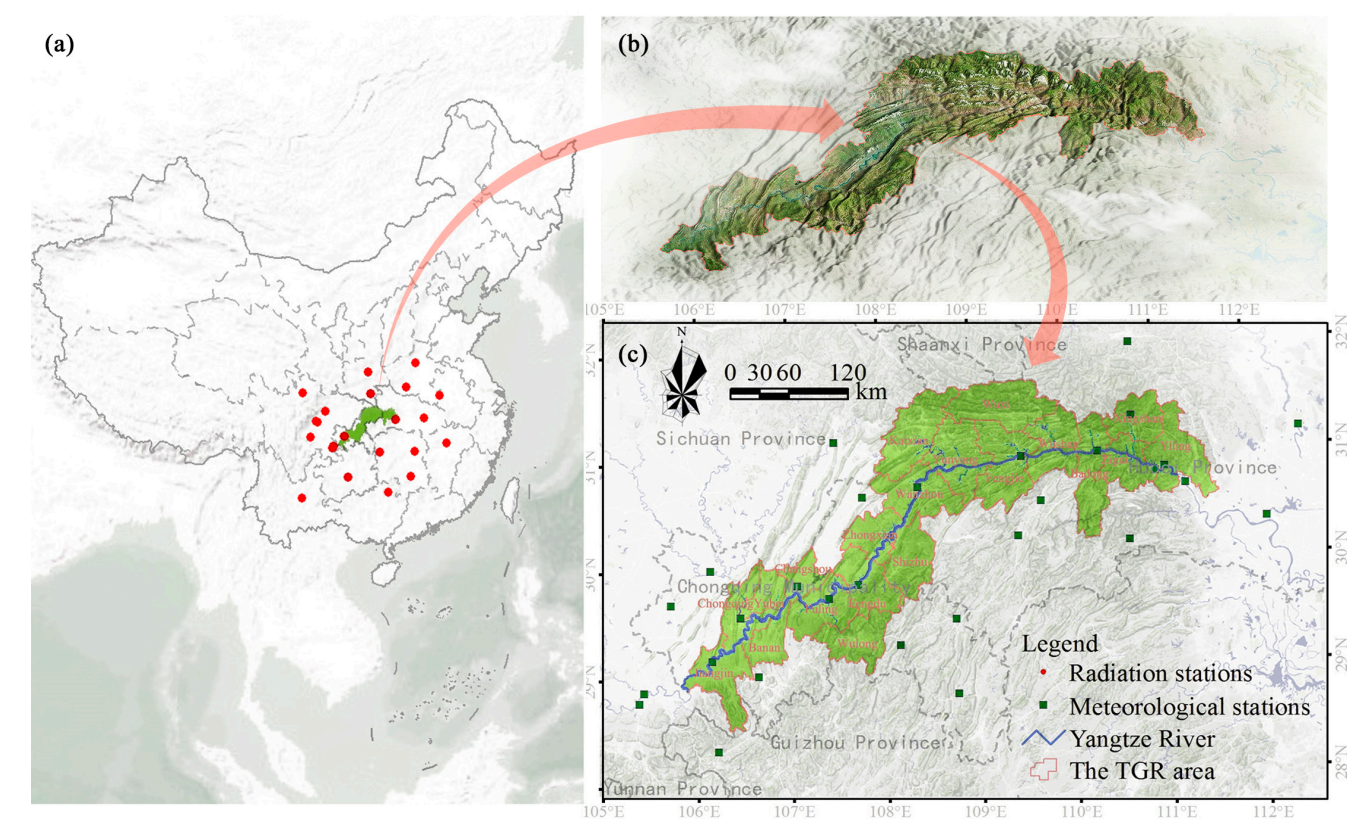

Figure 1. Locations of the radiation stations (a), the topographical characters of the Three Gorges Reservoir (TGR) area (b) and the meteorological stations of the precipitation and temperature data (c). 
Over the past decades, the Chinese government has launched a host of green infrastructure projects such as the Grain-to-Green Program, the Natural Forest Protection Program, and the Yangtze River Shelter Forest Project [35]. Forestland has significantly increased, while cropland has sharply declined [1]. These vital projects have actively contributed to promoting forest cover and ecosystem restoration, and the TGR area has gradually changed from an agricultural landscape to a forest landscape.

On the other hand, urbanization has significantly increased the proportion of built-up land due to a series of land use policies and incentives such as the Western Development Project. Meanwhile, storing water has altered the landscape of the TGR area. The Three Gorges Dam began to store water in 2003, and the water level reached $135 \mathrm{~m}$ in June 2003, $156 \mathrm{~m}$ in October 2006, and $175 \mathrm{~m}$ in October 2010 [36]. Impoundment submerged many forestlands and generated a special riparian zone, i.e., an ecozone between aquatic and terrestrial ecosystems, which has significantly influenced ecosystem structure.

\subsection{Data and Processing}

Data used in this study mainly including land use maps, climate data (e.g., precipitation, temperature, and radiation), MODIS-NDVI images, and DEM (Table 1). Land use maps of the TGR area in 2000, 2005, 2010, and 2015 were derived from Landsat TM/ETM+/OLI imageries with $30 \mathrm{~m}$ resolution using the supervised classification and artificial neural network methods, provided from our previous study $[1,35]$. The land use types included forestland (e.g., broad-leaved forest, coniferous forest, shrubby and mixed forest), grassland, cropland, water, built-up land, and bare land.

Table 1. The study data sources and their explanations.

\begin{tabular}{cc}
\hline Data & Data Source and Explanation \\
\hline Land use data & 30m resolution land use maps in 2000, 2005, 2010, and 2015 [35]. \\
\hline Radiation data & $\begin{array}{c}\text { Monthly total radiation data of 22 meteorological stations from } \\
2000 \text { to 2015 (http://data.cma.cn) }\end{array}$ \\
\hline Precipitation and temperature data & $\begin{array}{c}\text { Monthly total precipitation and mean temperature data of 29 } \\
\text { meteorological stations from 2000 to 2015 (http://data.cma.cn) }\end{array}$ \\
\hline NDVI images & $\begin{array}{c}\text { 250m resolution MODIS-NDVI products (MOD13Q1) from 2000 } \\
\text { to 2015 (http://modis.gsfc.nasa.gov/) }\end{array}$ \\
\hline DEM & $\begin{array}{c}\text { 30m resolution DEM derived from ASTER Global Digital } \\
\text { Elevation Model V002 (http://www.gscloud.cn/) }\end{array}$ \\
\hline
\end{tabular}

We collected the monthly radiation data of 22 meteorological stations during 2000-2015 from the National Meteorological Administration of China $[1,36]$. These meteorological stations distribute in or near the TGR area (Figure 1a). The ordinary kriging method was used to interpolate the monthly total radiation maps with $30 \mathrm{~m}$ resolution [36]. Meanwhile, we collected the monthly total precipitation and mean temperature data of 29 meteorological stations (Figure 1c). Considering the tremendous effect of topography on climate, the co-kriging method was used to interpolate the monthly total precipitation and mean temperature maps with $30 \mathrm{~m}$ resolution [1]. To obtain the monthly NDVI, the time-series MODIS-NDVI images were processed using the maximum value compositing algorithm at the pixel level [36]. 


\subsection{Estimating NPP}

\subsubsection{CASA Model}

As a light use efficiency model, the CASA was widely used to assess the NPP at the regional scale [31]. In this study, we employed it to calculate the monthly NPP (Equation (1)) and estimated the annual NPP of the TGR area by summing the twelve-monthly NPP:

$$
\mathrm{NPP}=\mathrm{APAR} \times \varepsilon
$$

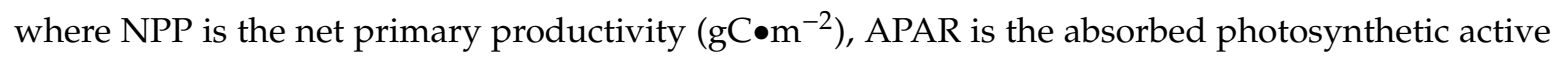
radiation $\left(\mathrm{MJ} \bullet \mathrm{m}^{-2} \bullet \mathrm{yr}^{-1}\right)$, and $\varepsilon$ is the light use efficiency $\left(\mathrm{gC} \bullet \mathrm{MJ}^{-1}\right)$.

\section{Calculating APAR}

Radiation is the vegetation photosynthesis energy source, but not all radiation could be absorbed. We used the interpolated monthly total radiation maps and the monthly NDVI as input data to calculate the APAR by employing the following equations [9,42]:

$$
\begin{aligned}
& \operatorname{APAR}(x, t)=\operatorname{SOL}(x, t) \times \operatorname{FPAR}(x, t) \times 0.5 \\
& \operatorname{FPAR}(x, t)=\frac{\operatorname{FPAR}(x, t)_{\mathrm{NDVI}}+\operatorname{FPAR}(x, t)_{\mathrm{SR}}}{2} \\
& \operatorname{FPAR}(x, t)_{\mathrm{NDVI}}=\frac{\left(\mathrm{NDVI}(x, t)-\mathrm{NDVI}_{i, \text { min }}\right)\left(\mathrm{FPAR}_{\mathrm{max}}-\mathrm{FPAR}_{\mathrm{min}}\right)}{\left(\mathrm{NDVI}_{i, \max }-\mathrm{NDVI}_{\mathrm{i}, \min }\right)}+\mathrm{FPAR}_{\text {min }} \\
& \operatorname{FPAR}(x, t)_{\mathrm{SR}}=\frac{\left(\mathrm{SR}(x, t)-\mathrm{SR}_{i, \text { min }}\right)\left(\mathrm{FPAR}_{\text {max }}-\mathrm{FPAR}_{\text {min }}\right)}{\mathrm{SR}_{i, \text { max }}-\mathrm{SR}_{i, \text { min }}}+\mathrm{FPAR}_{\text {min }} \\
& \operatorname{SR}(x, t)=\frac{1+\operatorname{NDVI}(x, t)}{1-\operatorname{NDVI}(x, t)}
\end{aligned}
$$

where, $\operatorname{APAR}(x, t)$ is absorbed photosynthetic active radiation in the geographic of a given location $x$ and $t$ month. $\operatorname{SOL}(x, t)$ is the total solar radiation in $x$ pixel and $t$ month; and $\operatorname{FPAR}(x, t)$ is the fraction of the photosynthetically active radiation absorbed by vegetation canopy in $x$ pixel and $t$ month, and could be determined by NDVI. SR $(x, t)$ is the simple ratio of NDVI in $x$ pixel and $t$ month. $\operatorname{FPAR}(x, t)_{\mathrm{NDVI}}$ and $\operatorname{FPAR}(x, t)_{\mathrm{SR}}$ respectively are FPAR calculated by NDVI and SR in $x$ pixel and $t$ month. FPAR max $_{\text {and }}$ FPAR $_{\min }$ represent the maximum and minimum values of FPAR in the TGR area, and are 0.950 and 0.001 in this study. $\operatorname{NDVI}(x, t)$ and $\operatorname{SR}(x, t)$ are the NDVI and SR in $x$ pixel and $t$ month, respectively. $\mathrm{NDVI}_{i, \text { min }}$ and $\mathrm{NDVI}_{i \text {, max }}$ refer to the minimum and maximum values of the NDVI for the land use type of $i$ in the $t$ month (Table 2). SR $i$, min and $\mathrm{SR}_{i, \max }$ refer to the minimum and maximum values of the SR for the land use type of $i$ in the $t$ month (Table 2). 
Table 2. Parameters of the CASA model for different land use types.

\begin{tabular}{cccccc}
\hline Land Use Type & NDVI $_{\text {max }}$ & $\mathbf{N D V I}_{\min }$ & $\mathbf{S R}_{\max }$ & $\mathbf{S R}_{\min }$ & $\varepsilon_{\max }$ \\
\hline Coniferous forest & 0.8889 & 0.0765 & 17.002 & 1.166 & 0.389 \\
\hline Mixed forest & 0.8852 & 0.0765 & 16.422 & 1.166 & 0.475 \\
\hline Evergreen broad-leaved forest & 0.8979 & 0.0765 & 18.589 & 1.166 & 0.985 \\
\hline Deciduous broad-leaved forest & 0.9058 & 0.0765 & 20.231 & 1.166 & 0.692 \\
\hline Shrubby & 0.8983 & 0.0765 & 18.666 & 1.166 & 0.429 \\
\hline Grassland & 0.7994 & 0.0765 & 8.970 & 1.166 & 0.542 \\
\hline Cropland & 0.7994 & 0.0765 & 8.970 & 1.166 & 0.542 \\
\hline Water, built-up land, and bare land & 0.7994 & 0.0765 & 8.970 & 1.166 & 0.542 \\
\hline
\end{tabular}

Assessing $\varepsilon$

The light use efficiency $(\varepsilon)$ is an important parameter for estimating NPP and could be affected by many environmental conditions such as temperature and moisture [31,42]. The interpolated monthly mean temperature maps were used to calculate two temperature stress coefficients, while the interpolated monthly mean temperature and total precipitation maps were used to conduct the moisture stress coefficient. Meanwhile, the maximum light-use efficiency under the ideal condition of different land use types was determined by an empirical method [42,43]:

$$
\varepsilon(x, \mathrm{t})=\mathrm{T}_{\varepsilon 1}(x, t) \times \mathrm{T}_{\varepsilon 2}(x, t) \times \mathrm{W}_{\mathcal{\varepsilon}}(x, t) \times \varepsilon_{\max }
$$

$$
\begin{gathered}
T_{\varepsilon 1}(x, t) \\
= \begin{cases}0, & \text { if the monthly mean temperture } \leq-10{ }^{\circ} \mathrm{C} \\
0.8+0.02 T_{\text {opt }}(x)-0.0005\left[T_{\text {opt }}(x)\right]^{2}, & \text { if the monthly mean temperture }>-10{ }^{\circ} \mathrm{C}\end{cases} \\
T_{\varepsilon 2}(x, t)=\frac{1.1814}{\left\{1+e^{0.2 \times\left[T_{\text {opt }}(x)-10-T(x, t)\right]}\right\} \times\left\{1+e^{\left.0.3 \times\left[-T_{\text {opt }}(x)-10+T(x, t)\right]\right\}}\right.} \\
W_{\varepsilon}(x, t)=0.5+\frac{0.5 \times E(x, t)}{E_{p}(x, t)}
\end{gathered}
$$

where, $\varepsilon(x, t)$ is the light use efficiency in $x$ pixel and $t$ month. $T_{\varepsilon 1}(x, t)$ and $T_{\varepsilon 2}(x, t)$ are temperature stress coefficients, and indicate the reduction of light-use efficiency caused by temperature factor. $W_{\varepsilon}(x, t)$ is the moisture stress coefficient, and reflects the reduction of light-use efficiency caused by the moisture factor. $\varepsilon_{\max }$ is the maximum light-use efficiency under the ideal condition for different land use types (Table 2). $T_{\text {opt }}(x)$ represents the optimal temperature of the land use type in the geographic of a given location $x$, and could be determined by the mean temperature in the month with the largest NDVI. $T(x, t)$ is the monthly mean temperature in $x$ pixel and $t$ month. $E(x, t)$ and $E_{p}(x, t)$ are the actual evapotranspiration and potential evapotranspiration in $x$ pixel and $t$ month, which could be determined by temperature and precipitation.

\subsubsection{Validation of NPP Estimation of the CASA Model}

It is challenging to obtain measured NPP data at the regional scale. Even if these data could be acquired, it seems impossible to ensure that the field data and the remote-sensing images are obtained in the same period. Although it is difficult to verify the NPP estimation accuracy of the model simulation, Wang et al. [32] documented that vegetation productivity is closely related to aboveground biomass. Therefore, the relationship between aboveground biomass and NPP could be conducted to validate the CASA model's NPP estimation. First, the aboveground biomass in some forest plots was calculated by using the field data according to Zeng et al. [43] in 2000 and 2013. Second, we used 
the plot boundary as the statistical unit to obtain the NPP estimation of the CASA model for these forest plots in 2000 and 2013. Third, the correlation analysis between the aboveground biomass and the NPP estimation was performed in 2000 and 2013. These significant positive relationships (Figure S1) indicated that the model's estimation accuracy was satisfactory, and the CASA model could support us to analyze the spatiotemporal variations of NPP in the TGR area.

\subsection{Scenario Design}

To decouple the effects of climate change, afforestation, urbanization, storing water and other land use changes on the NPP dynamic, we designed four scenarios to estimate the potential NPP of 2015 (Table S1). We fixed the precipitation, temperature, and radiation as the level of 2000 in all these scenarios, but changed the NDVI images and the land use map to estimate the potential NPP caused by different land use changes. In scenario A, we removed the effect of climate change and estimated the overall effect of all land use changes on NPP dynamics between 2000 and 2015 ( $\Delta L U C C)$. The effect of climate change could also be estimated because we hypothesize that the NPP was only influenced by climate conditions and land use changes.

Based on scenario A, we designed the other three scenarios: no afforestation (Scenario B), no urbanization (Scenario C), and no storing water (Scenario D). Then, we estimated the individual effects of afforestation, urbanization and storing water on the NPP dynamic and recorded them as $\triangle$ Afforestation, $\Delta$ Urbanization, and $\Delta$ Storing water (Table S1). Meanwhile, $\triangle L U C C$ consists of their effects and the effect of other land use changes ( $\Delta$ Others), expressed as Equation (11). Therefore, we could also calculate $\Delta$ Others according to the above four scenarios.

$$
\Delta L U C C=\Delta \text { Afforestation }+\Delta \text { Urbanization }+\Delta \text { Storing water }+\Delta \text { Others }
$$

\subsection{Statistical Analysis}

\subsubsection{Trend Analysis}

To display the change trends of the NPP and climate variables (e.g., precipitation, temperature, and radiation) during 2000-2015, we applied the least-square linear regression model to fit these variables for the whole TGR area and at the pixel scale [1,36]. The modeled slope was used to describe the change trends because this approach is simple and computationally efficient [1].

\subsubsection{Correlation Analysis}

As a nonparametric version of the Pearson product-moment correlation, Spearman's rank correlation analysis was carried out to examine the relationship between the annual NPP and climate variables for the whole TGR area and at the pixel level.

\subsubsection{Correspondence Analysis}

Correspondence analysis was employed to evaluate the relevance of NPP change with forest change types. This analysis had the potential to identify the relationship between afforestation and NPP dynamics. It was especially useful in light of spatial consistency. In applying correspondence analysis, scores were discretized to place the data into a contingency table [44]. In this study, scores could be discretized into several categories (e.g., increase, decrease, and no change) according to the results of trend analysis for annual NPP and forest coverage in the $1 \mathrm{~km}$ grid, and then newly categorized data can be analyzed with biplot embedded in the correspondence analysis. The biplot analysis embedded in correspondence analysis can visually examine the relationships between row and column categories in a plane constructed by a pair of dimensions to enhance understanding of the category relationships [44]. 


\section{Results}

\subsection{Dynamic of NPP from 2000 to 2015}

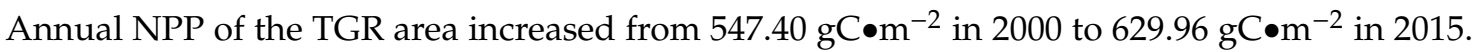
During this period, the maximum occurred in 2002 with the annual NPP of $645.73 \mathrm{gC} \mathrm{m}^{-2}$, while the

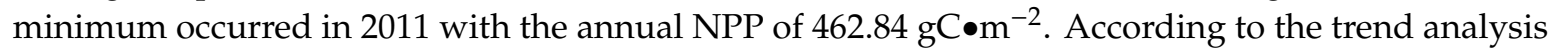
of the NPP time series, annual NPP of the TGR area presented an increasing trend with the rate of

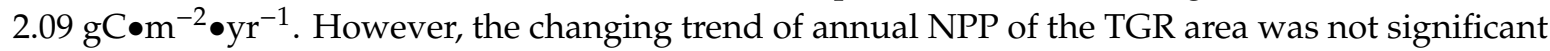
because the $p$-value of $t$-test for the modeled slope was far more than 0.05 (Figure 2a).

Meanwhile, the change trends of annual NPP varied among three slope zones (Figure $2 \mathrm{~b}$ ). The slopes of $<15^{\circ}, 15 \sim 25^{\circ}$, and $>25^{\circ}$ accounted for $46.23 \%, 29.03 \%$, and $24.74 \%$ of the total area in the TGR area, respectively. Although the annual NPP of the zone of slope $<15^{\circ}$ increased at a rate of

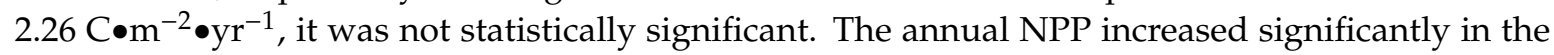

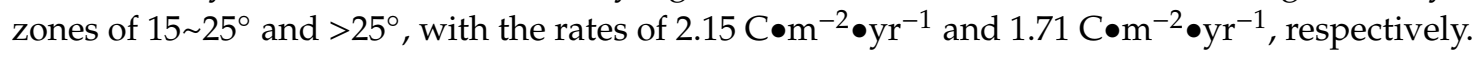
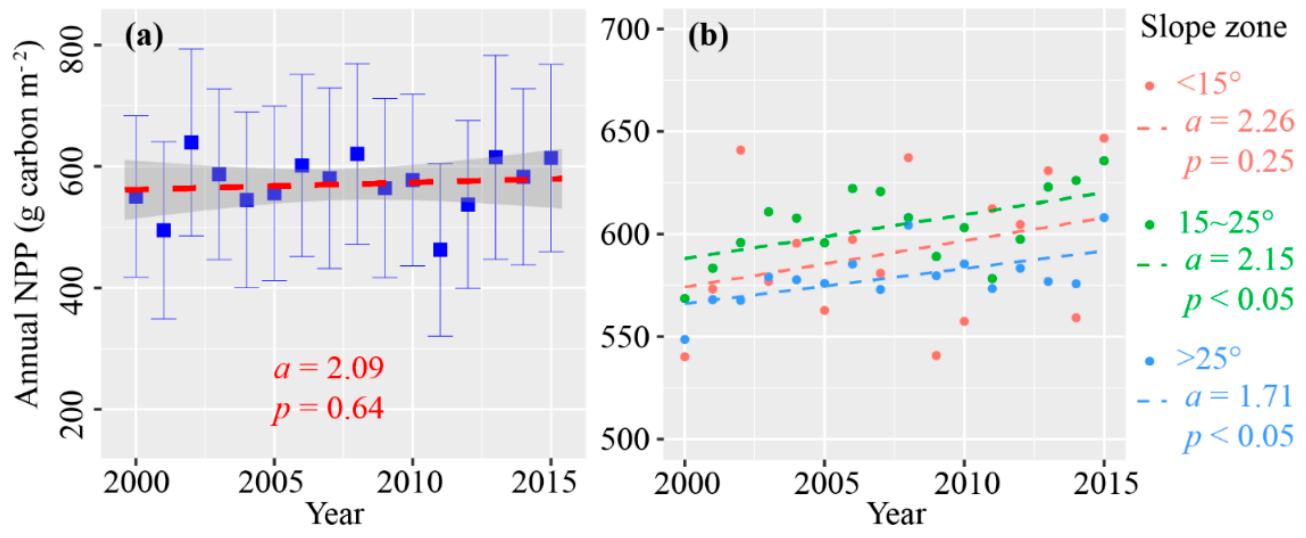

Figure 2. Temporal variation of annual NPP for the whole TGR area (a) and for different slope zones (b). Note: The dotted line indicates the linear fitting from 2000 to 2015, the a describes the changing trend. Meanwhile, the $t$ statistic was applied to test the significance of the modeled slope, and the $p$ value documents the significance. In the figure (a), error bars extending from the means document the standard deviation of Annual NPP, while the gray region is the $95 \%$ confidence intervals of the linear model.

\subsection{Spatial Variation of Annual NPP in the TGR Area}

To illuminate the spatial variation of annual NPP in the TGR area, the average and linear annual NPP trends were evaluated pixel by pixel from 2000 to 2015 (Figure 3). According to the average of annual NPP, the carbon sequestration exhibited a distinct spatial heterogeneity in the TGR area (Figure 3a). The average of annual NPP was lower in the southwest region than in the northeast region. Meanwhile, annual NPP increased slightly in the middle of the reservoir area, and the maximum

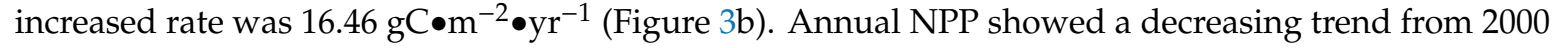
to 2015 for the pixels around the built-up area and on both sides of the Yangtze River. In these regions,

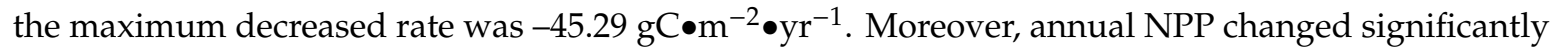
for the middle of the TGR area because the $p$ values of $t$-test for the modeled slope of these pixels were less than 0.05 (Figure 3c).

According to the linear trends of annual NPP and their significances, three NPP change types were defined and illuminated (Figure $3 \mathrm{~d}$ ). Although $48.82 \%$ of the total area had an increasing trend for annual NPP, only $21.19 \%$ of the total area presented a significant increase in annual NPP $(p<0.5)$, and these pixels were distributed in the middle of the TGR area. Although $15.16 \%$ of the total area had the decreasing trend for annual NPP, only 3.60\% of the TGR area presented a significant decrease in annual NPP $(p<0.5)$, mainly built-up areas and water in 2015 . Consequently, 36.03\% of the reservoir 
area showed no change in annual NPP at 0.05 statistically significant level, and 39.18\% of the TGR area changed insignificantly for annual NPP during 2000-2015.

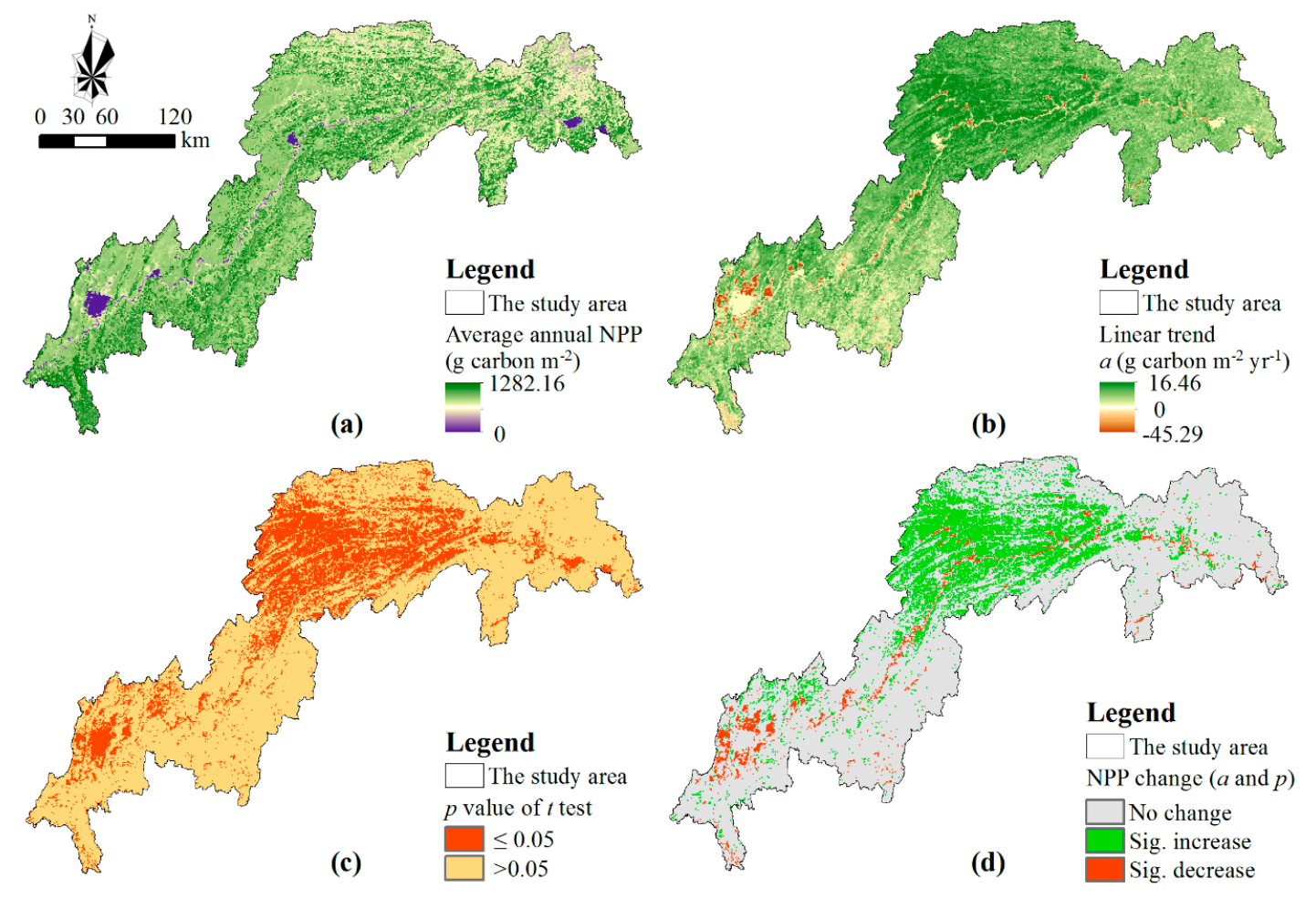

Figure 3. Spatiotemporal variations of annual NPP in the TGR area at the pixel level. Average annual NPP (a) change trends of annual NPP; (b), the $p$-value of t-test for the modeled slopes; (c), and the NPP change types (d). Note: The least-square linear regression model was applied to analyze the temporal variation of annual NPP from 2000 to 2015 for each pixel, and the changing trend is described by the modeled slope which is recorded by a in the figure (b). In the figure (d), No change documents that annual NPP did significantly no change $(\mathrm{a}=0$ and $p \leq 0.05)$ or changed but not significantly $(\mathrm{a} \neq 0$ and $p>0.05)$. Sig. increase documents annual NPP increased significantly ( $\mathrm{a}>0$ and $p \leq 0.05$ ), while Sig. decrease documents annual NPP decreased significantly ( $<<0$ and $p \leq 0.05$ ).

\subsection{Effects of Climate and Land Use Changes on NPP Dynamics}

Based on the scenario A, we conducted the potential annual NPP of 2015 induced by all land use changes $\left(\mathrm{NPP}_{\mathrm{A}}\right)$ with the value of $565.52 \mathrm{gC}^{-2}$. Converting annual NPP to annual carbon sequestration capacity, we knew the actual carbon sequestration capacities of the TGR area in 2000 and 2015 were $31.66 \mathrm{TgC}\left(1 \mathrm{Tg}=10^{12} \mathrm{~g}\right)$ and $36.79 \mathrm{TgC}$, respectively (Figure 4a). The potential carbon sequestration capacity of the TGR area in 2015 was $32.71 \mathrm{TgC}$ according to scenario A. Therefore, all land use changes could contribute to carbon sequestration capacity with $1.05 \mathrm{TgC}$, while climate changes could contribute to carbon sequestration capacity with $4.08 \mathrm{TgC}$.

Coupling the land use maps of 2000 and 2015, we reclassified these land use changes into the following four types (Figure S2): no change (79.8\%), afforestation (15.5\%), urbanization $(2.3 \%)$, storing water $(1.1 \%)$, and other land use changes $(1.2 \%)$. Afforestation was scattered throughout the TGR area, while built-up land expanded dramatically in the southwest, especially in Chongqing City. Storing water submerged the low-lying areas along the Yangtze River. In light of scenario B, afforestation was positively related to carbon sequestration, and could sequestrate carbon with the capacity of $2.04 \mathrm{TgC}$ for the whole TGR area (Figure $4 \mathrm{~b}$ ). However, urbanization and storing water both could release carbon with the capacity of $0.12 \mathrm{TgC}$ and $0.32 \mathrm{TgC}$ for the whole TGR area according to scenarios C and D. Meanwhile, we used the Equation (11) to calculate the effect of other land use 
changes and converted it into a carbon sequestration capacity of $-0.55 \mathrm{TgC}$, indicating other land use changes could also release carbon.

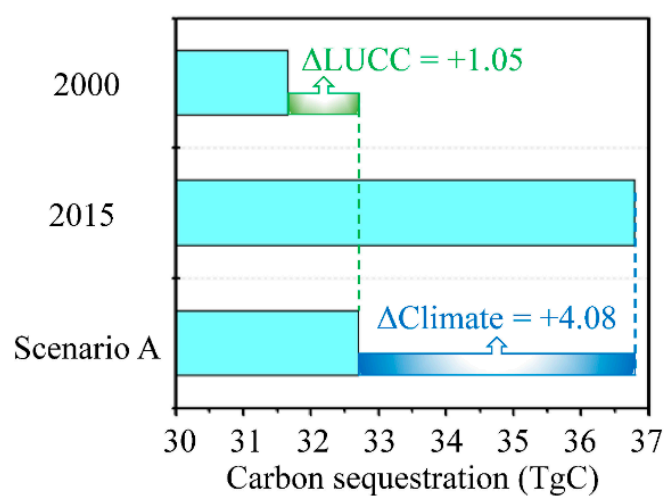

(a)

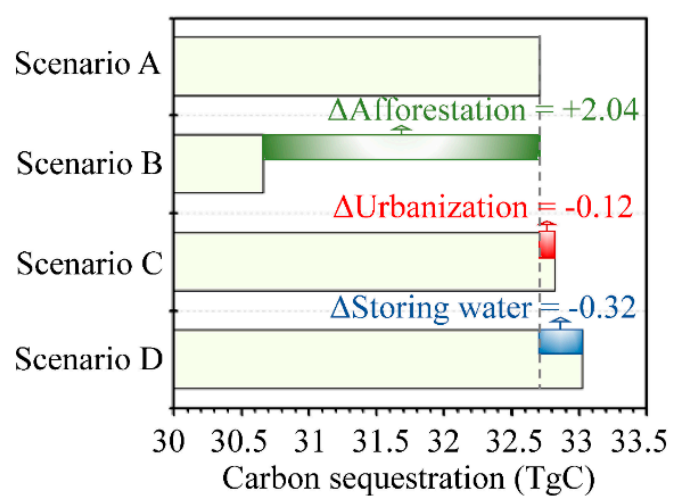

(b)

Figure 4. The effects of climate and all land use changes (a) and the effects of afforestation; urbanization and storing water (b) on NPP derived from annual carbon sequestration of the TGR area in 2000, 2015, and four scenarios. Note: $\triangle \mathrm{LUCC}$, the effect of all land use changes; $\Delta$ Climate, the effect of climate change; $\Delta$ Afforestation, the effect of afforestation; $\Delta$ Urbanization, the effect of urbanization; $\Delta$ Storing water, the effect of storing water. For each effect value $(\Delta)$, the number records the magnitude, while the plus or minus sign in front of the number indicates sequestrating or releasing carbon.

\subsection{Spatial Variations of the Individual Effect of Land Use Change}

According to four scenarios, we examined the effects of four land use changes on the NPP dynamics for 20 counties to illuminate the spatial variations (Figure 5). Overall, the combined effects of all land use changes would contribute to carbon sequestration in most counties except Chongqing. Afforestation made a great contribution to carbon sequestration and storage. The effect of afforestation on NPP dynamics was greater in the east-north reaches than in the west-south reaches (Figure 5a). Carbon sequestration capacities caused by afforestation were more than $100 \mathrm{GgC}\left(1 \mathrm{Gg}=10^{9} \mathrm{~g}\right)$ for these counties in east-north. The maximum was $134.42 \mathrm{GgC}$ in the Yunyang, while the minimum was 66.81 in Chongqing.

Urbanization would release carbon, and the individual effect exhibited a distinct spatial heterogeneity (Figure 5b). Chongqing presented the greatest effect with $-24.74 \mathrm{GgC}$, much higher than Yubei, which showed the second greatest effect with $-14.24 \mathrm{GgC}$. The effect was low in the middle reach of the TGR area and was only $-1.28 \mathrm{GgC}$ in Wuxi. Storing water would also release carbon, and the individual effect was larger for these counties along the Yangtze River (Figure 5c). Yunyang presented the greatest effect with the value of $-40.87 \mathrm{GgC}$, while Wuxi presented the smallest effect with the value of $-2.05 \mathrm{GgC}$. Meanwhile, other land use changes would release many carbons, and the capacity fluctuated between $-3.58 \mathrm{GgC}$ and $-51.34 \mathrm{GgC}$ (Figure $5 \mathrm{~d}$ ). 


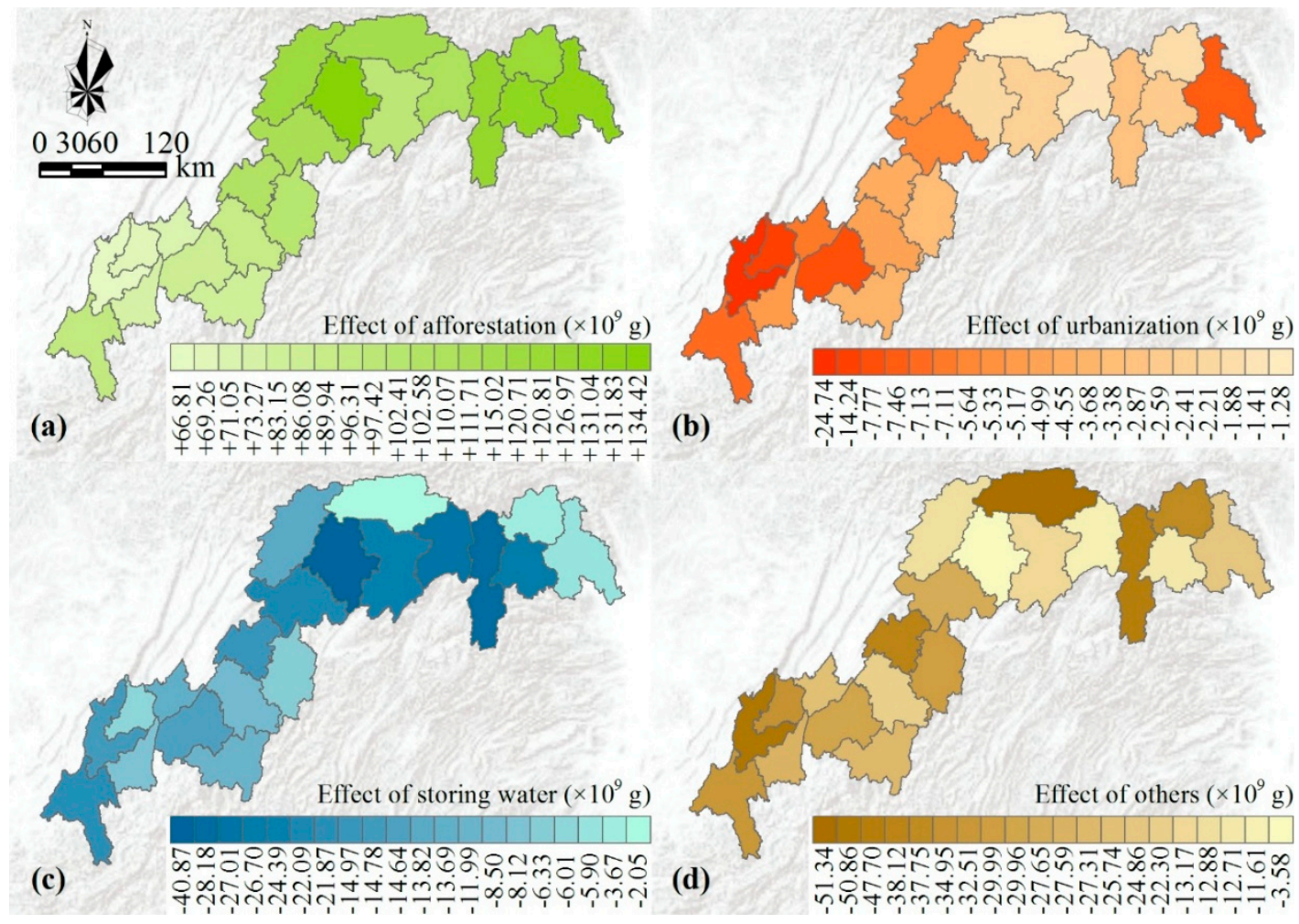

Figure 5. Spatial variations of the effects of afforestation (a); urbanization (b); storing water (c), and other land use changes (d) on NPP change at the county level.

\section{Discussion}

\subsection{Change in NPP of the TGR Area from 2000 to 2015}

According to the CASA model's estimation, annual NPP of the TGR area presented an increasing

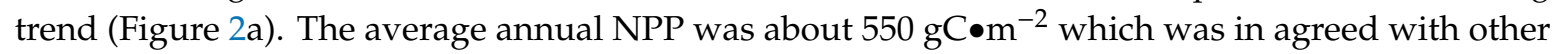
relevant studies [30,43]. Despite a lack of experimental validation, we used the correlation analysis to validate the estimation accuracy because the vegetation productivity was usually closely related to aboveground biomass [32]. Our estimated results are supported by the significantly strong positive relationship between the aboveground biomass and the NPP estimation (Figure S1).

The estimated NPP of the TGR area in our study agreed with relevant studies (such as Zeng et al. [43]) based on field experiments and a statistical model. Moreover, the spatiotemporal dynamics of annual NPP were consistent with other process-based model simulations. For instance, Chen and Xiao [30] used the Biome-BGC model to assess the NPP for different forests of the TGR area, and they reported that annual NPP showed an increasing trend during 1992-2012 and the average

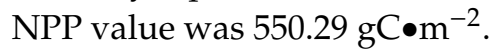

\subsection{Possible Effects of Climate Changes}

NPP is a sensitive indicator of climate change [12], and climate change could help to sequestrate $4.08 \mathrm{Tg}$ carbon for the whole TGR area between 2000 and 2015 (Figure 4a). The annual mean temperature of the TGR area was higher in $2015\left(17.37^{\circ} \mathrm{C}\right)$ than in $2000\left(16.47^{\circ} \mathrm{C}\right)$, and presented an insignificant increasing trend with the change rate of $0.03^{\circ} \mathrm{C} / \mathrm{yr}$ according to the change trend analysis (Figure S3(a1)). Meanwhile, the annual mean temperature had an increasing trend in most regions, especially in the middle reach of the TGR area (Figure 6(a1)). Temperature is a key factor affecting NPP, and some studies (such as Reyer et al. [29], Langerwisch et al. [19], Zhang et al. [45]) suggested NPP would increase with temperature because a warmer climate helps to enhance photosynthesis for vegetation 
growth, but some studies have indicated that NPP would decrease with temperature because a warmer climate helps to increase plant's autotrophic respiration [46,47]. Our results supported the former insight. Spearman's rank correlation between NPP and annual mean temperature was significant, and the correlation coefficient was 0.55 (Figure S3(a2)). The spatial explicit correlation coefficients were positive in most regions, and the maximum was 0.83 (Figure 6(a2)). Therefore, climate warming could partially explain the increasing NPP, and the increasing temperature may have a significant positive effect on the annual NPP of the TGR area in the future.

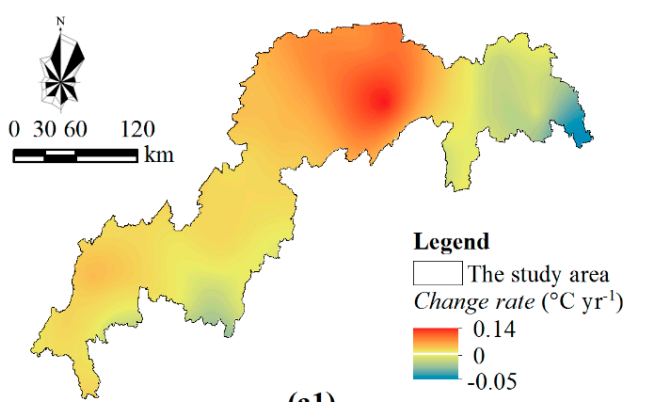

(a1)

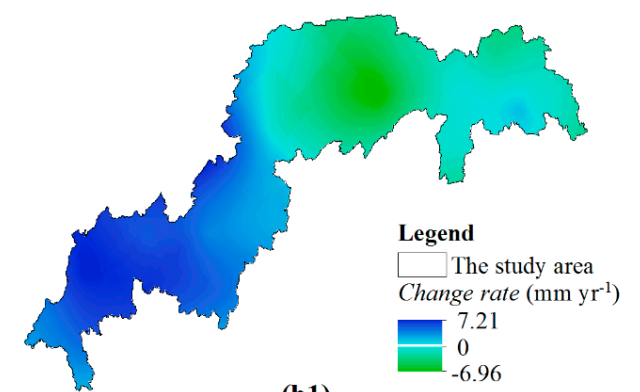

(b1)

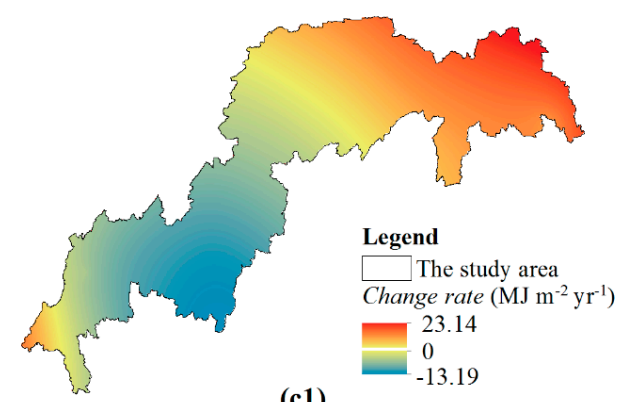

(c1)

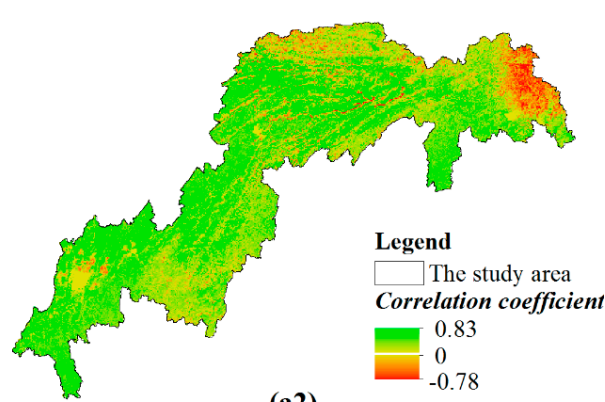

(a2)

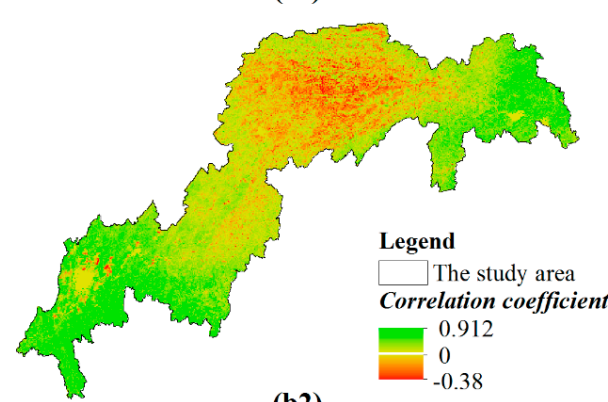

(b2)

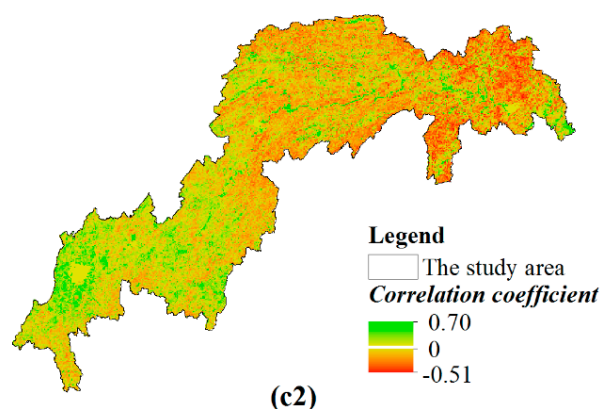

Figure 6. Spatial variation of climate variables and Spearman's rank correlations between the annual NPP and these variables for the period 2000-2015. Note: The least-square linear regression model was applied to analyze the temporal variations of these climate variables for each pixel, and the change trend is described by the modeled slope in the figures of $(\mathbf{a} \mathbf{1}, \mathbf{b} \mathbf{1}, \mathbf{c} \mathbf{1})$. The Spearman's rank correlation coefficient was applied to analyze the relationship between NPP and climate variable in the figures $(\mathbf{a} 2, \mathrm{~b} 2, \mathrm{c} 2)$.

As an important climatic factor, precipitation plays a key role in vegetation productivity [47]. According to the temporal variation (Figure S3(b1)), the TGR area's annual rainfalls were $1211.47 \mathrm{~mm}$ and $1181.34 \mathrm{~mm}$ in 2000 and 2015, respectively. The changing trend of annual rainfall exhibited significant heterogeneity (Figure 6(b1)). In the TGR area, the annual rainfall increased significantly in the west-south reach but decreased significantly in the east-north reach. Annual NPP was positively correlated with annual rainfall, and the Spearman's rank correlation coefficient was 0.49 (Figure S3(b2)). Moreover, the relationship between annual NPP and rainfall was positively in most regions but was negatively in the middle reach of the TGR area (Figure S3(b2)). It was not surprising to the positive relationship between annual NPP and rainfall because precipitation could improve plant 
photosynthesis [48]. However, the negative effect of rainfall on the NPP dynamics in the middle reach was difficult to explain. The topography of this reach was complex and rugged, and precipitation was higher in the TGR area, which could increase soil erosion according to our previous studies [36,49]. Soil loss could reduce soil organic matter content and indirectly reduce plant's productivity, which also was supported by other studies [9,50,51], especially in the high-precipitation regions. Therefore, soil conservation caused by declining rainfall may be partially responsible for the increasing NPP in the middle reach.

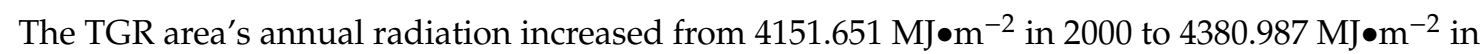
2015 , and the change rate was $15.28 \mathrm{MJ} \bullet \mathrm{m}^{-2} / \mathrm{yr}$ (Figure S3(c1)). Meanwhile, annual radiation showed an increasing trend in the east-north reach, but a decreasing trend in the west-south reach (Figure 6(c1)). Radiation was the only energy source, and the NPP dynamic usually was positively related to radiation. However, the correlation between annual NPP and radiation was weaker in our study, and the Spearman's rank correlation coefficient was only 0.17 (Figure S3(c2)). Meanwhile, NPP increased with radiation in most regions but decreased with radiation in some regions (Figure 6(c2)). According to the Spearman's rank correlation, most relationships between annual NPP and radiation were not significant. Therefore, we guessed the relative effect of radiation was weaker than that of temperature and rainfall on the NPP dynamic because the TGR area has a humid mid-subtropical monsoon climate with rich light and the radiation was not the limiting factor for plant's production [9,31]. Moreover, not only changes in climatic conditions but also atmospheric carbon dioxide $\left(\mathrm{CO}_{2}\right)$ concentrations, aerosol concentration, atmospheric factors, and other factors have been highlighted as possible causes of NPP dynamic $[6,21,25]$, the composite effect of these factors could alter the absorbed photosynthetic active radiation and then affect the relationship between annual NPP and radiation.

\subsection{Possible Effects of Land Use Changes}

To better document the responses of NPP to different land use changes in the TGR area, we used four simulation scenarios to decouple the combined and individual effects of land use changes (Figure $4 \mathrm{~b}$ ). The combined effect of all land use changes could sequestrate carbon with an annual capacity of $1.05 \mathrm{TgC}$, and afforestation made a considerable contribution. Forests played the most critical role in terrestrial carbon accumulation $[6,8,51]$. This could explain the positive contribution of the implementation of green infrastructure projects on annual NPP of the TGR area. Moreover, we used the $1 \mathrm{~km}$ grid to map the forest coverage change and annual NPP change and discussed their spatiotemporal relationships (Figure S4). The spatial coupling map between forest change and NPP change (Figure 7a) revealed that the regions with an increasing tendency of NPP and forest coverage were mainly concentrated in the middle of the TGR area, while that with a decreasing tendency mostly were cities and water areas. The grid number of both persisting forestland and no change in NPP was larger, and their relationship was strongly positive according to the correspondence analysis (Figure $7 \mathrm{~b}$ ). Therefore, we could conclude that afforestation and deforestation could partially explain the increase and decrease of annual NPP in the TGR area because of the spatiotemporal consistencies between NPP change and forest coverage change.

In a previous study [1], we have reported that deforestation was mainly caused by urbanization and storing water in the TGR area. We assessed their individual effects, and they could release $0.12 \mathrm{Tg}$ and $0.32 \mathrm{Tg}$ carbon for the whole TGR area, respectively (Figure $4 \mathrm{~b}$ ). According to the spatial variations, the individual effect of urbanization and storing water presented significantly heterogeneity (Figure 5). In detail, releasing carbon caused by urbanization was higher in the west-south than in the east-north, coinciding with these human activities about urban construction such as Western Development Project (Figure $5 b$ ). Meanwhile, releasing carbon caused by storing water was higher in the east-north than in the west-south. This is large because these east-north counties were more severely affected by the Three Gorges Dam (Figure 5c). Therefore, storing water and urbanization occurred in different regions, which led to the distinct spatial heterogeneity of potential carbon losses. 
Other land use changes such as degradation from forests to grasses only accounted for $1.2 \%$ of the TGR area and would release $0.55 \mathrm{Tg}$ carbon (Figure $5 \mathrm{~d}$ ). A series of ecological problems have seriously influenced terrestrial ecosystems due to the complex human activities and the rugged topography [38,39], leading to land degradation and desertification in the reservoir area. Although other land use changes would bring adverse ecological effects and release carbon, the Chinese government has employed many ecological restoration policies since 2000, which could offset these negative effects $[20,35]$. Thus, green infrastructure projects should be maintained and implemented adequately and sustainably in the future and play a greater role in offsetting potential carbon losses.
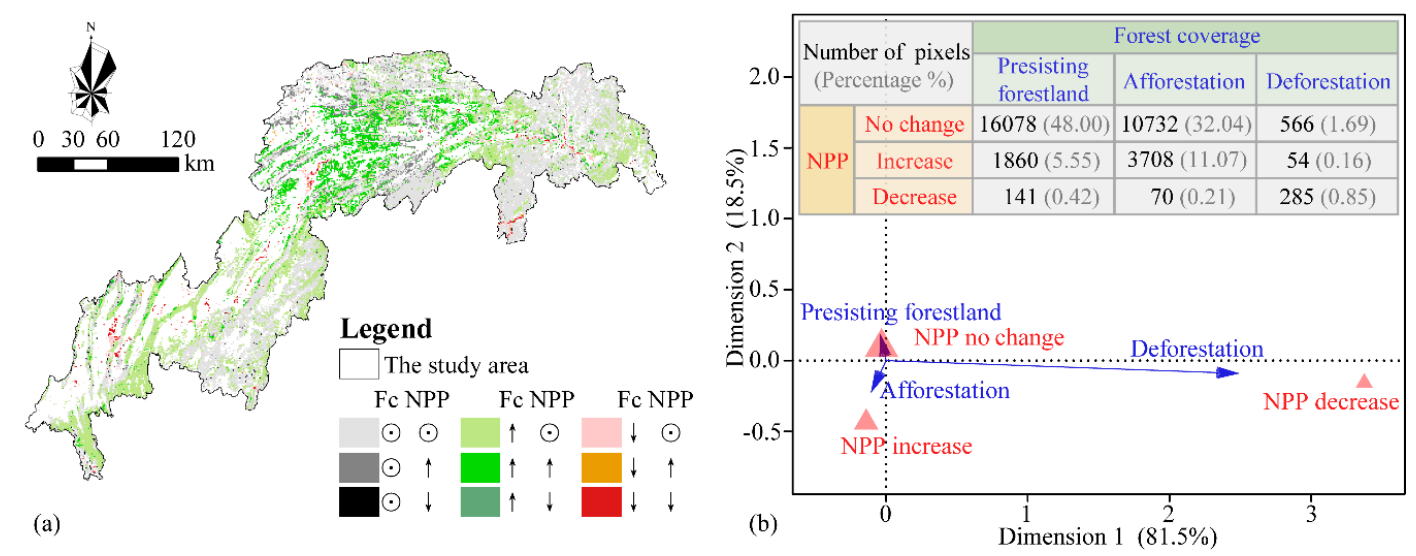

Figure 7. Spatial coupling map (a) and correspondence analysis; (b) between NPP change and forest change. Note: In the figure (a), Fc is an acronym for forest coverage, while $\odot, \uparrow$ and $\downarrow$ indicate no change, increase, and decrease, respectively.

\subsection{Land Use Policies and Implications}

Over the decades, many green infrastructure projects have been implemented in China to improve the ecosystem structure $[1,20,35]$. However, human activities such as urbanization expansion and the hydropower construction of the Three Gorges Dam have accelerated the degradation of ecosystem functions [1]. Multiple land use changes presented confounded, and interactive effects on NPP dynamics $[9,19]$. The combined effect of all land use changes would effectively improve carbon sequestration in the TGR area (Figure 5a). Our results demonstrated that afforestation could positively promote terrestrial carbon sequestration by enhancing vegetation coverage, and offset carbon losses caused by human activities such as urbanization and storing water. On one hand, afforestation converted the degraded land or sloping cropland to forestation, increasing vegetation production in the unit and the efficiency of terrestrial carbon sequestration [20,51]. On the other hand, the magnitude of the positive effect caused by vegetation restoration was larger than the negative effect caused by urbanization and other economic activities because the green infrastructure projects always were implemented on a larger scale with a long duration. Therefore, although multiple land use changes could occur simultaneously and would bring both positive and negative ecological effects, the implementation of green infrastructure projects such as afforestation could partly offset the negative ecological effect.

To achieve regional sustainable development, it is a vital issue for planning and designing the efficient green infrastructure [52,53]. Forest landscapes in mountains usually have strong ecological functions, because these green infrastructures mainly consist of native coniferous and broad-leaved species with faster growth and strong adaptability and would provide larger carbon sequestration capacity. The section of the forest landscape presented that the broad-leaved forests are in the low altitude, the mixed forests are in the middle altitude, and the coniferous forests are in the high altitude (Figure 8a). Meanwhile, agroforestry landscapes could provide both economic values and ecosystem services which differ in quantity and quality from conventional agricultural practices, and consist of ecological forests and economic forests such as tea gardens and orchards in the TGR area (Figure 8b). 
Urban green spaces have ecological, social, and economic functions, and could provide multiple or cross-cutting services such as recreation, aesthetics and air purification (Figure 8c). The special riparian corridors usually consist of shrubs and herbs in the TGR area, and this landscape is an ecotone between aquatic and terrestrial ecosystems (Figure 8d). Because the TGR area has the complex topographical characters and various landscapes, it is urgent and important to provide more proper and feasible landscape planning schemes of green infrastructure for the corresponding landscape in the future.
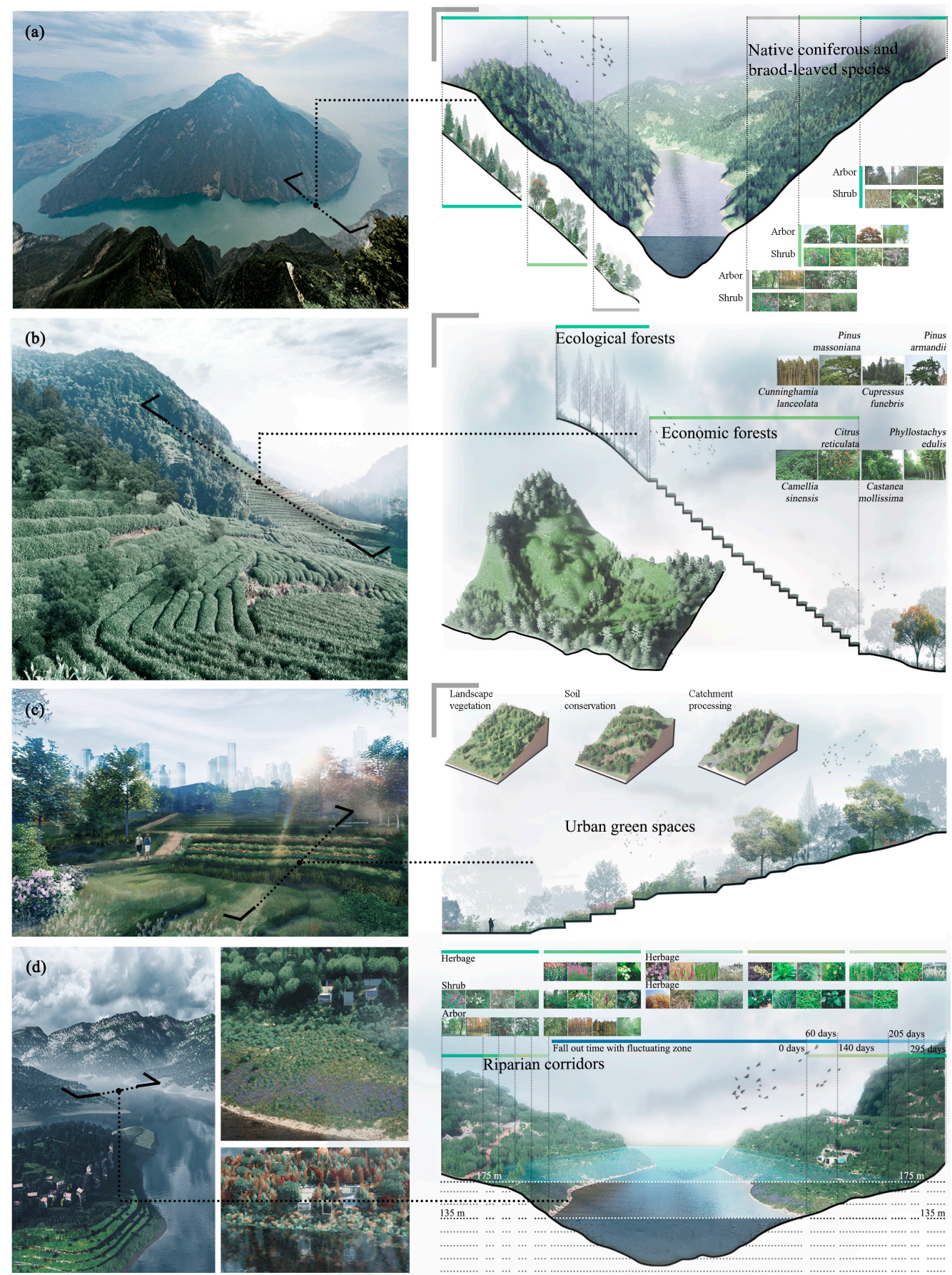

Figure 8. Green infrastructure planning and designing for ecological forest landscape (a); agroforestry landscape (b); urban green space (c) and riparian corridor (d) in the TGR area. Note: The left pictures illuminate the complex topographical characters and various landscapes, while the right pictures are our planning and designing sections of green infrastructure for these landscapes. 


\subsection{Study Limitations}

Remote sensing data and the NPP model could help us understand the spatiotemporal variations of terrestrial NPP at the regional scale. Nevertheless, due to the inaccuracies of data and the inherent limitations of the CASA model [31,33], uncertainties still exist. First, the spatial maps of temperature, precipitation, and radiation were generated by geospatial interpolation from the climatic observations of meteorological stations, and uncertainties are inevitable. The second source of uncertainty for modeled NPP came from the downscaling of MODIS-NDIV products. Third, an increasing number of studies demonstrated that atmospheric processes, such as increasing atmospheric carbon dioxide concentrations [24,25] and nitrogen deposition [23,54], would affect the plant's production. As a common issue, the CASA model takes account of some climatic factors but not atmospheric factors, which is a limitation for NPP estimation.

Although there were some limitations and uncertainties for assessing NPP, all of the studies reviewed so far note it as the greatest challenge. Moreover, our study focused more on the spatiotemporal variations than the accuracy of estimated NPP, and we believed the model's estimation accuracy was to meet our demand.

\section{Conclusions}

Although critical for estimating various land use changes and their ecological effects, previous studies have failed to decouple the respective and the combined effects of different land use changes on ecosystem services. Based on the estimation of CASA model, the terrestrial NPP of the TGR area presented an increasing trend during 2000-2015. Meanwhile, we conducted that climate change and land use change both could contribute to carbon sequestration in the TGR area according to the scenario design. However, land use changes could bring both positive and negative ecological effects simultaneously over the past decades. Among these land use changes, only afforestation could sequestrate carbon, indicating that green infrastructure had effectively offset the carbon emissions. Although urbanization and storing water both released carbon, these land use changes and their negative ecological effects exhibited significantly spatial heterogeneity. Urbanization-induced carbon emission was larger in the southwest than in the northeast, while impoundment-induced carbon emission was larger for these counties along the Yangtze River. Green infrastructure has effectively offset the carbon emissions from urbanization and storing water in the TGR area, which provides some fundamental supports for further ecological restoration and contributes to empowering land use policies towards carbon sequestration and storage at the regional scale.

Supplementary Materials: The following are available online at http://www.mdpi.com/1660-4601/17/21/8077/s1, Table S1. Scenario design for quantifying the effects of climate change and land use changes on the NPP dynamic. Figure S1. The relationship between the aboveground biomass and the NPP estimation of CASA. Figure S2. Spatial explicit land use changes derived from land use maps of the TGR area in 2000 and 2015. Figure S3. Temporal variations of climate variables and Spearman's rank correlations between annual NPP and these variables in the total area of the TGR area, China. Figure S4. Spatiotemporal variations of the forest coverage in the TGR area, China.

Author Contributions: Conceptualization, Q.L. and C.H.; methodology, C.H.; software, Q.L.; validation, Q.L. and Z.W.; formal analysis, Q.L. and Z.W.; resources, C.H.; writing—original draft preparation, Q.L.; writing-review and editing, C.H.; visualization, Q.L. and Z.W.; supervision, C.H.; project administration, Q.L. and C.H. All authors have read and agreed to the published version of the manuscript.

Funding: This work is sponsored by the Natural Science Foundation of China (Grant number 42001218) and the National Social Science Fund of China (Grant number 19BG133).

Acknowledgments: The authors also would like to thank the anonymous reviewers for their constructive comments on improving this paper.

Conflicts of Interest: The authors declare no conflict of interest. 


\section{References}

1. Huang, C.; Huang, X.; Peng, C.; Zhou, Z.; Teng, M.; Wang, P. Land use/cover change in the Three Gorges Reservoir area, China: Reconciling the land use conflicts between development and protection. Catena 2019, 175, 388-399. [CrossRef]

2. Han, Z.; Song, W.; Deng, X.; Xu, X. Grassland ecosystem responses to climate change and human activities within the Three-River Headwaters region of China. Sci. Rep. 2018, 8, 1-13. [CrossRef] [PubMed]

3. Li, Q.; Zhang, C.-L.; Shen, Y.; Jia, W.; Li, J. Quantitative assessment of the relative roles of climate change and human activities in desertification processes on the Qinghai-Tibet Plateau based on net primary productivity. Catena 2016, 147, 789-796. [CrossRef]

4. Li, J.; Zou, C.; Li, Q.; Xu, X.; Zhao, Y.; Yang, W.; Zhang, Z.; Liu, L. Effects of urbanization on productivity of terrestrial ecological systems based on linear fitting: A case study in Jiangsu, eastern China. Sci. Rep. 2019, 9, 17140. [CrossRef]

5. McDonough, L.K.; Santos, I.R.; Andersen, M.S.; O'Carroll, D.M.; Rutlidge, H.; Meredith, K.; Oudone, P.; Bridgeman, J.; Gooddy, D.C.; Sorensen, J.P.R.; et al. Changes in global groundwater organic carbon driven by climate change and urbanization. Nat. Commun. 2020, 11, 1-10. [CrossRef] [PubMed]

6. Payne, N.J.; Cameron, D.A.; Leblanc, J.-D.; Morrison, I.K. Carbon storage and net primary productivity in Canadian boreal mixedwood stands. J. For. Res. 2019, 30, 1667-1678. [CrossRef]

7. Xiao, D.; Deng, L.; Kim, D.; Huang, C.; Tian, K.; Dong-Gill, K. Carbon budgets of wetland ecosystems in China. Glob. Chang. Biol. 2019, 25, 2061-2076. [CrossRef]

8. Xiong, Y.; Cakir, R.; Phan, S.M.; Ola, A.; Krauss, K.W.; Lovelock, C.E. Global patterns of tree stem growth and stand aboveground wood production in mangrove forests. For. Ecol. Manag. 2019, 444, 382-392. [CrossRef]

9. Zhang, Y.; Song, C.; Zhang, K.; Cheng, X.; Band, L.E.; Zhang, Q. Effects of land use/land cover and climate changes on terrestrial net primary productivity in the Yangtze River Basin, China, from 2001 to 2010. J. Geophys. Res. Biogeosciences 2014, 119, 1092-1109. [CrossRef]

10. Thompson, S.D.; Nelson, T.A.; Coops, N.C.; Wulder, M.A.; Lantz, T.C. Global spatial-temporal variability in terrestrial productivity and phenology regimes between 2000 and 2012. Ann. Am. Assoc. Geogr. 2017, 107, 1519-1537. [CrossRef]

11. Tang, G.; Beckage, B. Projecting the distribution of forests in New England in response to climate change. Divers. Distrib. 2010, 16, 144-158. [CrossRef]

12. Harris, J.A.; Hobbs, R.J.; Higgs, E.; Aronson, J. Ecological restoration and global climate change. Restor. Ecol. 2006, 14, 170-176. [CrossRef]

13. Zhang, Y.; Zhang, C.; Wang, Z.; Chen, Y.; Gang, C.; An, R.; Li, J. Vegetation dynamics and its driving forces from climate change and human activities in the Three-River Source Region, China from 1982 to 2012. Sci. Total. Environ. 2016, 563, 210-220. [CrossRef]

14. Morel, A.C.; Adu Sasu, M.; Adu-Bredu, S.; Quaye, M.; Moore, C.; Ashley Asare, R.; Mason, J.; Hirons, M.; McDermott, C.L.; Robinson, E.J.Z.; et al. Carbon dynamics, net primary productivity (NPP) and human appropriated NPP (HANPP) across a forest-cocoa farm landscape in West Africa. Glob. Change Biol. 2019, 25, 2661-2677. [CrossRef]

15. Chen, Y.; Xu, N.; Yu, Q.; Guo, L. Ecosystem service response to human disturbance in the Yangtze River economic belt: A case of Western Hunan, China. Sustainability 2020, 12, 465. [CrossRef]

16. Wu, S.; Zhou, S.; Chen, D.; Wei, Z.; Dai, L.; Li, X. Determining the contributions of urbanisation and climate change to NPP variations over the last decade in the Yangtze River Delta, China. Sci. Total. Environ. 2014, 472, 397-406. [CrossRef]

17. Gingrich, S.; Niedertscheider, M.; Kastner, T.; Haberl, H.; Cosor, G.; Krausmann, F.P.; Kuemmerle, T.; Müller, D.; Reith-Musel, A.; Jepsen, M.R.; et al. Exploring long-term trends in land use change and aboveground human appropriation of net primary production in nine European countries. Land Use Policy 2015, 47, 426-438. [CrossRef]

18. Khalifa, M.; Elagib, N.A.; Ribbe, L.; Schneider, K. Spatio-temporal variations in climate, primary productivity and efficiency of water and carbon use of the land cover types in Sudan and Ethiopia. Sci. Total. Environ. 2018, 624, 790-806. [CrossRef] 
19. Langerwisch, F.; Václavík, T.; Von Bloh, W.; Vetter, T.; Thonicke, K. Combined effects of climate and land-use change on the provision of ecosystem services in rice agro-ecosystems. Environ. Res. Lett. 2017, 13, 015003. [CrossRef]

20. Deng, L.; Liu, S.; Kim, D.G.; Peng, C.; Sweeney, S.; Shangguan, Z. Past and future carbon sequestration benefits of China's grain for green program. Glob. Environ. Chang. 2017, 47, 13-20. [CrossRef]

21. Gower, S.T.; Kucharik, C.J.; Norman, J.M. Direct and indirect estimation of leaf area index, fAPAR, and net primary production of terrestrial ecosystems. Remote. Sens. Environ. 1999, 70, 29-51. [CrossRef]

22. Xu, B.; Pan, Y.; Plante, A.F.; McCullough, K.; Birdsey, R. Modeling forest carbon cycle using long-term carbon stock field measurement in the Delaware River Basin. Ecosphere 2017, 8, 01802. [CrossRef]

23. Tharammal, T.; Bala, G.; Narayanappa, D.; Nemani, R. Potential roles of $\mathrm{CO}_{2}$ fertilization, nitrogen deposition, climate change, and land use and land cover change on the global terrestrial carbon uptake in the twenty-first century. Clim. Dyn. 2018, 52, 4393-4406. [CrossRef]

24. Campioli, M.; Malhi, Y.; Vicca, S.; Luyssaert, S.; Papale, D.; Peñuelas, J.; Reichstein, M.; Migliavacca, M.; Arain, M.A.; Janssens, I.A. Evaluating the convergence between eddy-covariance and biometric methods for assessing carbon budgets of forests. Nat. Commun. 2016, 7, 13717. [CrossRef] [PubMed]

25. Wang, X.; Wang, C.; Bond-Lamberty, B. Quantifying and reducing the differences in forest $\mathrm{CO}_{2}$-fluxes estimated by eddy covariance, biometric and chamber methods: A global synthesis. Agric. For. Meteorol. 2017, 247, 93-103. [CrossRef]

26. Sannigrahi, S. Modeling terrestrial ecosystem productivity of an estuarine ecosystem in the Sundarban Biosphere Region, India using seven ecosystem models. Ecol. Model. 2017, 356, 73-90. [CrossRef]

27. Nguyen, H.-P.; Liu, J.; Zio, E. A long-term prediction approach based on long short-term memory neural networks with automatic parameter optimization by Tree-structured Parzen Estimator and applied to time-series data of NPP steam generators. Appl. Soft Comput. 2020, 89, 106116. [CrossRef]

28. Peng, C.; Liu, J.; Dang, Q.; Apps, M.J.; Jiang, H. TRIPLEX: A generic hybrid model for predicting forest growth and carbon and nitrogen dynamics. Ecol. Model. 2002, 153, 109-130. [CrossRef]

29. Reyer, C.P.O.; Flechsig, M.; Lasch-Born, P.; Van Oijen, M. Integrating parameter uncertainty of a process-based model in assessments of climate change effects on forest productivity. Clim. Chang. 2016, 137, 395-409. [CrossRef]

30. Chen, Y.; Xiao, W. Estimation of forest NPP and carbon sequestration in the Three Gorges Reservoir Area, using the biome-BGC model. Forests 2019, 10, 149. [CrossRef]

31. Zhu, W.; Pan, Y.; He, H.; Yu, D.; Hu, H. Simulation of maximum light use efficiency for some typical vegetation types in China. Chin. Sci. Bull. 2006, 51, 457-463. [CrossRef]

32. Wang, H.; Li, X.; Long, H.; Gai, Y.; Wei, D. Monitoring the effects of land use and cover changes on net primary production: A case study in China's Yongding River basin. For. Ecol. Manag. 2009, 258, 2654-2665. [CrossRef]

33. Waring, R.H.; Landsberg, J.; Linder, S. Tamm Review: Insights gained from light use and leaf growth efficiency indices. For. Ecol. Manag. 2016, 379, 232-242. [CrossRef]

34. Matsushita, B.; Xu, M.; Chen, J.; Kameyama, S.; Tamura, M. Estimation of regional net primary productivity (NPP) using a process-based ecosystem model: How important is the accuracy of climate data? Ecol. Model. 2004, 178, 371-388. [CrossRef]

35. Huang, C.B.; Teng, M.J.; Zeng, L.X.; Zhou, Z.X.; Xiao, W.F.; Zhu, J.H.; Wang, P.C. Long-term changes of land use/cover in the Three Gorges Reservoir Area of the Yangtze River, China. Ying Yong Sheng Tai Xue Bao J. Appl. Ecol. 2018, 29, 1585-1596. [CrossRef]

36. Huang, C.; Zhou, Z.; Teng, M.; Wu, C.; Wang, P. Effects of climate and land use/cover changes on soil loss in the Three Gorges Reservoir area, China. Geogr. Sustain. 2020. [CrossRef]

37. Xu, X.; Tan, Y.; Yang, G.; Li, H.; Su, W. Impacts of China's Three Gorges Dam Project on net primary productivity in the reservoir area. Sci. Total Environ. 2011, 409, 4656-4662. [CrossRef] [PubMed]

38. Shen, Z.; Qiu, J.; Hong, Q.; Chen, L. Simulation of spatial and temporal distributions of non-point source pollution load in the Three Gorges Reservoir Region. Sci. Total. Environ. 2014, 493, 138-146. [CrossRef] [PubMed]

39. Wu, J.; Huang, J.; Han, X.; Xie, Z.; Gao, X. Three Gorges Dam-Experiment in habitat fragmentation? Science 2003, 300, 1239-1240. [CrossRef] 
40. Zhao, X.; Zhou, W.Z.; Tian, L.; He, W.H.; Zhang, J.C.; Liu, D.H.; Yang, F. Effects of land-use changes on vegetation net primary productivity in the Three Gorges Reservoir Area of Chongqing. Acta Ecol. Sinica 2018, 38, 7658-7668. (In Chinese)

41. Xiao, Q.; Xiong, Q.; Pan, K. What is left for our next generation? Integrating ecosystem services into regional policy planning in the Three Gorges Reservoir area of China. Sustainability 2018, 11, 3. [CrossRef]

42. Yu, D.; Shi, P.; Shao, H.; Zhu, W.; Pan, Y. Modelling net primary productivity of terrestrial ecosystems in East Asia based on an improved CASA ecosystem model. Int. J. Remote. Sens. 2009, 30, 4851-4866. [CrossRef]

43. Zeng, L.; Wang, P.; Xiao, W. Estimating vegetation biomass and productivity and their distribution patterns in the Three Gorges Reservoir region. Acta Ecol. Sinica 2008, 28, 3808-3816. (In Chinese)

44. Greenacre, M. Correspondence Analysis in Practice, 3rd ed.; Informa UK Limited: New York, NY, USA, 2017. [CrossRef]

45. Zhang, X.; Xiao, W.; Wang, Y.; Wang, Y.; Wang, H.; Wang, Y.; Zhu, L.; Yang, R. Spatial-temporal changes in NPP and its relationship with climate factors based on sensitivity analysis in the Shiyang River Basin. J. Earth Syst. Sci. 2019, 129, 1-13. [CrossRef]

46. Girardin, M.P.; Hogg, E.H.; Bernier, P.Y.; Kurz, W.A.; Guo, X.J.; Cyr, G. Negative impacts of high temperatures on growth of black spruce forests intensify with the anticipated climate warming. Glob. Chang. Biol. 2015, 22, 627-643. [CrossRef] [PubMed]

47. El Masri, B.; Schwalm, C.; Huntzinger, D.N.; Mao, J.; Shi, X.; Peng, C.; Fisher, J.B.; Jain, A.K.; Tian, H.; Poulter, B.; et al. Carbon and water use efficiencies: A comparative analysis of ten terrestrial ecosystem models under changing climate. Sci. Rep. 2019, 9, 1-9. [CrossRef]

48. Zhang, B.; Tan, X.; Wang, S.; Chen, M.; Chen, S.; Ren, T.; Xia, J.; Bai, Y.; Huang, J.; Han, X. Asymmetric sensitivity of ecosystem carbon and water processes in response to precipitation change in a semi-arid steppe. Funct. Ecol. 2017, 31, 1301-1311. [CrossRef]

49. Teng, M.; Huang, C.; Wang, P.; Zeng, L.; Zhou, Z.; Xiao, W.; Huang, Z.; Liu, C. Impacts of forest restoration on soil erosion in the Three Gorges Reservoir area, China. Sci. Total. Environ. 2019, 697, 134164. [CrossRef]

50. Shahbaz, M.; Kuzyakov, Y.; Heitkamp, F. Decrease of soil organic matter stabilization with increasing inputs: Mechanisms and controls. Geoderma 2017, 304, 76-82. [CrossRef]

51. Deng, L.; Kim, D.-G.; Peng, C.; Shangguan, Z. Controls of soil and aggregate-associated organic carbon variations following natural vegetation restoration on the Loess Plateau in China. Land Degrad. Dev. 2018, 29, 3974-3984. [CrossRef]

52. Martí, P.; García-Mayor, C.; Nolasco-Cirugeda, A.; Serrano-Estrada, L. Green infrastructure planning: Unveiling meaningful spaces through Foursquare users' preferences. Land Use Policy 2020, 97, 104641. [CrossRef]

53. Liao, Q.; Chen, R.; Huang, S. Study on Landscape Evaluation of Abandoned Mining Area Based on Fuzzy Comprehensive Evaluation and GIS. Geo. Sci. Tech. Inform. 2019, 38, 241-250. [CrossRef]

54. Deng, L.; Huang, C.; Kim, D.; Shangguan, Z.; Wang, K.; Song, X.; Peng, C. Soil GHG fluxes are altered by N deposition: New data indicate lower $\mathrm{N}$ stimulation of the $\mathrm{N}_{2} \mathrm{O}$ flux and greater stimulation of the calculated C pools. Glob. Chang. Biol. 2020, 26, 2613-2629. [CrossRef]

Publisher's Note: MDPI stays neutral with regard to jurisdictional claims in published maps and institutional affiliations.

(C) 2020 by the authors. Licensee MDPI, Basel, Switzerland. This article is an open access article distributed under the terms and conditions of the Creative Commons Attribution (CC BY) license (http://creativecommons.org/licenses/by/4.0/). 